\title{
Calidad bacteriológica del agua
} \section{para consumo humano en zonas} de alta marginación de Chiapas

\author{
Héctor Javier Sánchez-Pérez, Ph. D., (1) María Guadalupe Vargas-Morales, Q.F.B., (1) \\ José Domingo Méndez-Sánchez, Q.F.B. ${ }^{(2)}$
}

\section{Sánchez-Pérez HJ, Vargas-Morales MG, Méndez-Sánchez JD. Calidad bacteriológica del agua para consumo humano en zonas de alta marginación de Chiapas Salud Publica Mex 2000;42:397-406.}

\section{Resumen}

Objetivo.Analizar la calidad bacteriológica del agua (CBA) para consumo humano y su relación con diarreas y enteroparasitosis en niños de I a I4 años en comunidades de alta marginación socioeconómica de Chiapas, México. Material y métodos. En una muestra aleatoria de 99 viviendas de la Región Fronteriza de Chiapas, de marzo a septiembre de 1998, se recolectaron muestras de agua para consumo humano, se indagó sobre diarreas en los últimos 15 días y se recolectaron muestras de heces de 322 niños de I a I4 años. La CBA se determinó mediante la técnica de filtración por membranas y las enteroparasitosis por el método de Faust. Se utilizó el estadístico $\chi^{2}$ para el análisis de la CBA con relación a los diversos factores analizados. Resultados. Sólo $31 \%$ de las muestras de agua fueron aptas para consumo humano. La CBA y la presencia de diarreas referida por las madres de los menores no mostraron asociación. Los niños con mala CBA en sus viviendas mostraron mayor prevalencia de Entamoeba histolytica y mayor tendencia a estar parasitados. Conclusiones. Es necesario desarrollar medidas que mejoren la CBA y campañas de educación que incrementen el uso de agua hervida, su manejo adecuado y el cuidado de las fuentes de abastecimiento comunitarias.

Palabras clave: calidad del agua; abastecimiento de agua; coliformes totales; coliformes fecales; Entamoeba histolytica; México

\author{
Sánchez-Pérez HJ, Vargas-Morales MG, \\ Méndez-Sánchez JD. \\ Bacteriological quality \\ of drinking water in areas of high levels \\ of poverty in Chiapas, Mexico. \\ Salud Publica Mex 2000;42:397-406.
}

\begin{abstract}
Objective.To analyze the bacteriological quality of drinking water (BQDW) and its association with diarrhoea and intestinal parasites in children I to I4 years old, in areas of high levels of poverty in Chiapas, Mexico. Material and methods. From March to September 1998, drinking water was collected from a random sample of 99 households in the Border Region of Chiapas, Mexico; data on diarrhoeal disease (in the past 15 days) were collected and stool testing for intestinal parasites was performed in children I to 14 years old $(n=322)$. The BQDW was determined by the filtration membrane technique. Intestinal parasitic infections were determined by the Faust Method.The $\chi^{2}$ statistic was used to analyse factors associated with BQDW. Results. Only $31 \%$ of the water samples were adequate for human consumption. The BQDW and the presence of diarrhoea (informed by the mothers of the children) showed no association. Children living in households with inadequate BQDW had a higher prevalence of Entamoeba histolytica and a greater tendency to have intestinal parasites. Conclusions. It is necessary to develop programs that improve BQDW and to develop education efforts aimed at increasing the use of boiled water and the adequate management and care of community water storage sites.
\end{abstract}

Key words: water quality; water supply; total coliforms; fecal coliforms; Entamoeba histolytica; Mexico

La realización de este trabajo fue posible gracias al financiamiento del Consejo Nacional de Ciencia y Tecnología (Fondo SIBEJ, convocatoria 1997).

(I) Area de Población y Salud, El Colegio de la Frontera Sur, San Cristóbal de las Casas, Chiapas, México.

(2) Sección de Patógenos, Laboratorio del Centro de Investigación de Paludismo, Instituto Nacional de Salud Pública, Tapachula, Chiapas, México.

Fecha de recibido: 22 de febrero de 2000 - Fecha de aprobado: 17 de agosto de 2000

Solicitud de sobretiros: Dr. Héctor Javier Sánchez Pérez. El Colegio de la Frontera Sur. Carretera Panamericana y Periférico Sur s/n, 29290 San Cristóbal de las Casas, Chiapas, México.

Correo electrónico: hsanchez@sclc.ecosur.mx 
W 1 agua es un factor que puede convertirse en un vehículo para la adquisición de diversas enfermedades en el ser humano. ${ }^{1,2}$ Actualmente, existen descritas más de 20 enfermedades en las que el agua actúa directa o indirectamente en su aparición, algunas de ellas con alto impacto en términos de morbilidad y mortalidad. $^{2}$

México enfrenta diversos problemas de abastecimiento de este recurso tales como escasez ${ }^{3}$ y contaminación. ${ }^{4-6}$ En las zonas rurales los principales problemas de disponibilidad del agua son el desabasto y su falta de potabilización. En numerosas ocasiones el agua que llega a las viviendas de muchas comunidades rurales proviene de manantiales, ríos, arroyos, ojos de agua $\mathrm{u}$ otro tipo de fuentes naturales superficiales expuestas a la contaminación debidas a la exposición y arrastre de partículas orgánicas e inorgánicas.

Existen diversos factores que influyen en la calidad del agua que consume una población. Entre éstos se encuentran: la presencia o ausencia de fuentes de abastecimiento naturales de agua; la infraestructura de redes de almacenamiento y distribución de agua; los aspectos culturales y socioeconómicos que condicionan la aceptación o rechazo a ciertas formas de abastecimiento y potabilización de agua y, por último, factores políticos que afectan la normatividad relativa a la inversión en el desarrollo y mantenimiento de sistemas de abastecimiento de agua potable.

Sin embargo, las poblaciones con menor acceso a sistemas que garanticen la disponibilidad de agua po- table para consumo humano son las poblaciones de mayor marginación socioeconómica. ${ }^{7}$ México, y en particular el estado de Chiapas, no escapa a esta situación. Según cifras del Censo de Población y Vivienda de $1990,{ }^{8}$ 20\% de las viviendas en México no disponía de agua entubada, mientras que en Chiapas esta cifra alcanzó $41 \%$ de sus viviendas a pesar de la gran cantidad de recursos hidrológicos existentes en esta entidad.

De acuerdo con información verbal proporcionada, en 1998, por la Comisión Nacional del Agua, por la Comisión Estatal del Agua y por el Instituto de Salud en el Estado de Chiapas (Secretaría de Salud -SSA-), no existen estudios en este estado para determinar la calidad bacteriológica del agua en poblaciones que no cuentan con una fuente de abastecimiento formal, como es el caso de las zonas rurales. Los estudios de control de calidad del agua únicamente se concentran en las áreas urbanas con sistemas de potabilización y se realizan mediante determinaciones de cloro residual. Asimismo, sólo dos ciudades en esta entidad cuentan con planta potabilizadora de agua: Tuxtla Gutiérrez (la capital) y Tapachula.

Chiapas es también uno de los estados mexicanos que presenta los mayores índices de enfermedades infectocontagiosas ${ }^{9,10}$ (cuadro I), muchas de las cuales se encuentran estrechamente relacionadas con el abasto y la calidad del agua para consumo humano. En 1997, Chiapas fue el estado que presentó la mayor tasa de mortalidad por enfermedades infecciosas intestinales del país, con una tasa de 23.9 defunciones por 100000

\section{INCIDENCIA DE ENFERMEDADES INFECCIOSAS Y PARASITARIAS. MÉXICO, MARZO A SEPTIEMBRE DE 1998}

\begin{tabular}{|c|c|c|c|}
\hline Enfermedad & Nacional & Chiapas & Región Fronteriza \\
\hline Absceso hepático amibiano (A06.4) & 6.65 & 15.88 & ND \\
\hline Amibiasis intestinal (A06.0-A06.3,A06.9) & 1675.99 & 2984.30 & 4974.0 \\
\hline Ascariasis (B77) & 470.66 & I 054.62 & 1719.8 \\
\hline Fiebre tifoidea (A0I.0) & 12.00 & 21.61 & ND \\
\hline Giardiasis (A07.I) & 81.53 & 97.21 & 190.4 \\
\hline Infecciones intestinales por otros organismos y las mal definidas (A04,A08-A09) & 5218.91 & 3574.56 & 3223.6 \\
\hline Otras infecciones intestinales debidas a protozoarios (A07.0,A07.2-A07.9) & 114.15 & 204.80 & 2052.8 \\
\hline Oxiuriasis (B80) & 133.69 & 259.76 & 421.5 \\
\hline Paratifoidea y otras salmonelosis (A0I.I-A02) & 223.53 & 616.27 & 455.8 \\
\hline Shigelosis (A03) & 47.14 & 175.86 & 713.9 \\
\hline Teniasis (B68) & 3.18 & 6.87 & ND \\
\hline
\end{tabular}

Tasas de incidencia sin estandarizar por 100000 habitantes

ND: no documentado

Fuente: Referencia II

Secretaría de Salud, Instituto de Salud en el Estado de Chiapas. Diagnóstico de salud 1998-1999. Comitán, Chiapas: SSA, Instituto de Salud en el Estado, Jurisdicción Sanitaria No. III, 2000. Documento no publicado 
habitantes, cifra que contrasta con el promedio nacional de 7.8, y con el del estado de Durango, entidad en la que dicha tasa se situó en 2.4 con igual denominador. ${ }^{12}$

Debido a las dos circunstancias anteriormente descritas (inexistencia de estudios sobre la calidad del agua para consumo humano y alta morbilidad y mortalidad por enfermedades gastrointestinales en Chiapas, muchas de ellas asociadas al consumo del agua) y en el contexto de un proyecto de evaluación de las condiciones sociales y de salud de la Región Fronteriza de Chiapas, * se analizó la calidad bacteriológica del agua para consumo humano (en función de diversos indicadores demográficos, socioeconómicos y de acceso a los servicios de salud) en comunidades de alta y muy alta marginación socioeconómica de esta región, y su relación con morbilidad percibida (diarreas) en los últimos 15 días, así como con enteroparasitosis en niños de 1 a 14 años de edad.

\section{Material y métodos}

La Región Fronteriza de Chiapas es una de las nueve regiones económicas que conforman este estado. Su población estimada, para 1995, fue de 425300 habitantes, ${ }^{13}$ distribuidos en 12 municipios. ${ }^{\ddagger}$ De éstos, 11 son considerados de alta y muy alta marginación so-

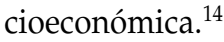

El estudio del que este trabajo forma parte* se realizó de marzo a septiembre de 1998, en 32 comunidades de la Región Fronteriza de Chiapas que se seleccionaron de manera aleatoria a partir de dos variables de interés: a) acceso a los servicios de salud -medido mediante la distancia de las comunidades a la unidad de salud de primer nivel de atención más cercana $(<1$ hora $-\geq 1$ hora) $-{ }^{15}$ y b) clasificación socioeconómica del municipio al que pertenecen (alta y muy alta marginación)..$^{14}$

En cuanto al análisis de la calidad bacteriológica del agua (CBA) para consumo humano y su relación con diarreas y enteroparasitosis en menores de 1 a 14 años de edad, el procedimiento seguido para la selección de viviendas $(n=99)$ se muestra en el cuadro II.

\footnotetext{
* Sánchez Pérez HJ, Jansá JM, Ochoa Díaz H, Halperin D, Martín MM, Caylá J. Proyecto de investigación Hacia un mejor control de la tuberculosis pulmonar en el estado de Chiapas, México. El Colegio de la Frontera Sur, Instituto Municipal de la Salud de Barcelona, Secretaría de Salud, Programa IMSS-Solidaridad. Barcelona, San Cristóbal de las Casas, Chiapas, 1996.

$\ddagger$ Secretaría de Salud, Instituto de Salud en el Estado de Chiapas. Programa de Ampliación de Cobertura para la Región Fronteriza de Chiapas 1997. Comitán, Chiapas: SSA, Instituto de Salud en el Estado, Jurisdicción Sanitaria No. III, 1997. Documento no publicado.
}

De manera adicional, en 10 de las 32 comunidades estudiadas, en que no se contaba con un sistema formal de abastecimiento de agua, también se recolectaron muestras de agua (extradomiciliarias) de las principales fuentes de abastecimiento para el análisis de su calidad bacteriológica. Estas 10 comunidades se ubicaron en municipios de muy alta marginación y en ellas los propios habitantes habían implementado sus propios sistemas de abastecimiento (por ejemplo, por medio de mangueras, que iban de las fuentes de abastecimiento -como ríos, ojos de agua, etc.- a las viviendas) o bien tomaban el agua directamente de las fuentes de abastecimiento público -ríos, pozos, etcétera.

Para la recolección de las muestras de agua se utilizaron vasos recolectores estériles con tapa de rosca, obteniéndose muestras de al menos 100 mililitros. Para su conservación se utilizaron hieleras de unicel con gel congelante a una temperatura inferior a $10^{\circ} \mathrm{C}$. Para la recolección de las muestras de agua en las viviendas seleccionadas, se pedía "un vaso de agua para tomar", y en el momento en que las personas de la casa iban a dar el agua para beber, se pedía permiso para tomar directamente las muestras de los recipientes en donde se almacenaba el agua. Las muestras se tapaban inmediatamente, se etiquetaban y se depositaban en una hielera para su conservación y posterior traslado al laboratorio. En el caso de las muestras extradomiciliarias $(n=10)$ se procedió según el tipo de fuente de abastecimiento de agua. Las procedentes de ríos $(n=2)$ se obtuvieron en el lugar donde la comunidad tomaba el agua para consumo (normalmente en la parte media del río). Las tomas de muestras de ojos de agua $(n=6)$ y de pozos $(n=1)$ se recolectaron lo más alejado posible de las orillas, procurando no tocar las paredes de los pozos y tratando de agitar lo menos posible el agua de esos lugares. En el caso de pozos profundos $(n=1)$, debido a que no se contaba con medios adecuados para hacer la recolección, las muestras de agua se tomaron utilizando primeramente una cubeta y del agua recolectada en la cubeta se tomó la muestra. Para la recolección de muestras no se utilizaron agentes desclorantes ni quelantes.

Así, para determinar la CBA se empleó al grupo de coliformes, tal como lo señala la Norma Oficial Mexicana para la Salud Ambiental, Agua para Uso y Consumo Humano, así como otros organismos en el ámbito internacional. ${ }^{16-20}$ Las muestras de agua analizadas fueron clasificadas en dos grupos, dependiendo del contenido de bacterias coliformes: agua de buena calidad, hasta 2 unidades formadoras de colonias (UFC)/100 ml de coliformes totales y ausencia de fecales y agua de mala calidad, tres o más UFC/100 ml de coliformes totales, independientemente del número de coliformes fecales. ${ }^{16} \mathrm{La}$ CBA se estimó mediante 


\title{
Cuadro II \\ Metodología de selección de viviendas para el anÁlisis de calidad del agua para consumo humano. MÉXICO, 1998
}

\author{
Viviendas estudiadas en proyecto de investigación enfocado al análisis de las condiciones sociales y de salud en la Región Fronteriza* $\mathrm{n}=\mathrm{I} 874$ \\ Número de viviendas seleccionadas para obtener muestras de agua \\ $\mathrm{n}=99$ \\ Criterios para fijar número de viviendas a estudiar la calidad bacteriológica del agua para consumo humano \\ - Número de viviendas en las localidades (una de cada 20 viviendas en promedio) \\ - Aspectos logísticos (viabilidad de conservación y transporte de muestras) \\ - Presupuesto disponible \\ Procedimiento de selección de las 99 viviendas estudiadas \\ I. De las I 874 viviendas estudiadas, una de cada cuatro se seleccionaron de manera aleatoria sistemática para recolección \\ de muestras de heces (para análisis coprológico en población de I a 14 años) \\ 2. De las 466 viviendas, se obtienen muestras de heces en $85 \%$ de ellas (tasa de no respuesta $=15 \%$ ) \\ 3. De estas 396 viviendas, selección aleatoria sistemática de una de cada cuatro para análisis de calidad bacteriológica del agua \\ para consumo humano

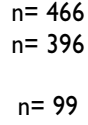

* Sánchez-Pérez HJ, Jansá JM, Ochoa Díaz H, Halperin D, Martín MM, Caylá J. Proyecto de investigación, Hacia un mejor control de la tuberculosis pulmonar en el Estado de Chiapas, México. San Cristóbal de las Casas, Chiapas, México: El Colegio de la Frontera Sur, Instituto Municipal de la Salud de Barcelona, Secretaría de Salud, Programa IMSS-Solidaridad, 1996

métodos directos, utilizando la técnica de filtración por membrana, con pruebas presuntivas y confirmatorias. ${ }^{17,21,22}$

Para la identificación de coliformes totales se utilizó el medio de cultivo de Agar Endo. ${ }^{17}$ En la realización de pruebas presuntivas y confirmatorias se empleó el caldo lactosado y el caldo verde brillante, respectivamente. La temperatura de incubación empleada fue de $37{ }^{\circ} \mathrm{C} \pm 0.5^{\circ} \mathrm{C}$ durante $24-30$ horas.

El rango de volúmenes de agua filtrados para los análisis de la CBA varió de los 0.01 a los $100 \mathrm{ml}$ en función de la densidad bacteriana esperada para cada tipo de muestra analizada (a peores condiciones higiénicas, menores volúmenes de agua filtrados). De esta manera, se facilitó la cuantificación del crecimiento de colonias y se evitó la inhibición del crecimiento por superpoblación. ${ }^{17,21}$ Aquí cabe señalar que en los casos en que se filtraron menos de $100 \mathrm{ml}$ se aforaron con solución tampón para obtener la dilución a $100 \mathrm{ml}$.

Para la lectura de resultados las colonias rojas con brillo metálico fueron consideradas como coliformes totales. Las colonias rojas sin brillo fueron verificadas mediante pruebas confirmatorias. Por su parte, las colonias rosadas, azules, blancas o incoloras sin brillo se consideraron no coliformes.

Respecto a la identificación de coliformes fecales el medio de cultivo utilizado fue el caldo M-FC con ácido rosólico. Aquí se debe señalar que, con el fin de aumentar la probabilidad de detectar este grupo de coliformes, los volúmenes de agua filtrados variaron en el rango de 5 a $100 \mathrm{ml}$, dependiendo de la calidad del agua analizada. La temperatura de incubación para la identificación de este grupo de coliformes fue de $44{ }^{\circ} \mathrm{C} \pm 0.5^{\circ} \mathrm{C}$ en baño María, durante 24 horas como máximo, con una humedad relativa de $95-100 \%$. Para la lectura de resultados se contabilizaron las colonias azules que crecieron en las membranas. Posteriormente, a una submuestra aleatoria de 36 muestras que resultaron positivas para este grupo de coliformes (de un total de 46 muestras que dieron positivo a este grupo) se le realizó la prueba confirmatoria de fermentación de la lactosa, utilizando un medio selectivo para Escherichia coli (caldo EC) a $44^{\circ} \mathrm{C} \pm 0.5^{\circ} \mathrm{C}$.

Las variables que se utilizaron para el análisis de la CBA fueron: a) demográficas, tamaño de la localidad ( $\geq 2500$ habitantes -urbanas- y $\leq 2499$-rurales), lengua indígena (condición de hablar o no alguna lengua indígena del jefe del hogar de las viviendas), y presencia de niños menores de cinco años en las viviendas; b) socioeconómicas, estrato socioeconómico del municipio (alta-muy alta marginación), ${ }_{1}^{14}$ escolaridad del jefe del hogar (0-3 años de estudio y $\geq 4$ años), ocupación del jefe del hogar (agrícola - no agrícola); indicadores de la vivienda como son tipo de piso (con o sin recubrimiento), tipo de combustible utilizado para cocinar (leña o gas), tipo de eliminación de excretas (retrete, a ras del suelo o letrina) y tenencia de luz (sí - no); y c) de acceso a servicios de salud, distancia de la comunidad a la unidad de salud más cercana $(<1$ hora $\mathrm{y} \geq 1$ hora). ${ }^{15}$

Por otra parte, los datos relativos a la presencia de diarreas en los últimos 15 días en los menores de 1 a 14 años $(n=322)$ se recopilaron de la siguiente manera: a los adultos de las viviendas estudiadas se les leyó 
un listado de enfermedades y síntomas orientadores en las que se incluyó a la diarrea como uno de los posibles problemas de salud. De esta manera, las madres de los niños señalaban quiénes de los niños, de 1 a 14 años, habían padecido diarrea ("corrimiento", "chorro", etc.) en los 15 días previos a la encuesta.

Respecto al procedimiento de la toma de muestras de heces para la determinación de enteroparasitosis, a las madres (o tutores) de todos los niños y niñas de 1 a 14 años de las viviendas estudiadas $(\mathrm{n}=99)$ se les solicitaron tres muestras de heces de cada uno de sus hijos en ese intervalo de edad, durante tres días consecutivos, comenzando con la primer muestra al día siguiente de la realización de la entrevista.

A las madres de los niños se les entregó un vaso copropac, en cuyo interior se había depositado previamente solución FAF (feno-alcohol-formaldehido), ${ }^{23,24}$ así como tres palillos de madera para ser utilizados en cada una de las muestras. A las madres se les explicó el procedimiento para la recolección y mezclado de las muestras con la solución FAF. Las muestras de heces fueron recogidas por el personal de campo del proyecto en las propias viviendas estudiadas. De los 322 niños a quienes se les solicitaron las tres muestras de heces (100 niños de 1 a 4 años y 222 de 5 a 14 años), se pudieron recolectar completas en 255 de ellos (tasa de no respuesta de $15 \%$ en los menores de 1 a 4 y de $23 \%$ en los de 5 a 14 años). Las muestras fueron almacenadas y transportadas en hieleras de unicel de las comunidades al laboratorio de patógenos del Centro de Investigación en Paludismo (CIP), de Tapachula, Chiapas, lugar donde se procesaron mediante la técnica de flotación del método de Faust. ${ }^{25,26}$ Una vez procesadas las muestras mediante el método de Faust, éstas fueron observadas al microscopio con objetivos de 10X y 40X, con el empleo de lugol parasitológico (solución saturada de cristales de yodo al 1\% de KI) sobre las preparaciones.

Respecto a la identificación del género Entamoeba, $E$. histolytica y E. coli éstas se diferenciaron con base en su morfología microscópica (tamaño, forma y número de núcleos, morfología del cariosoma, así como tipo de distribución de su cromatina periférica). ${ }^{25,27}$

Para el análisis de la CBA con relación a los distintos factores analizados, mediante el estadístico $\chi^{2}$, así como para el cálculo de razón de momios e intervalos de confianza se utilizó un nivel de significación de $95 \%$ de confianza.

\section{Resultados}

En las 99 viviendas en que se tomaron muestras de agua se censaron 718 habitantes, de éstos $322(45 \%)$ tuvie- ron entre 1 y 14 años de edad. El nivel de escolaridad promedio en la población mayor de 14 años fue de 3.5 años ( $22 \%$ no tenía escolaridad alguna y solamente $8 \%$ contaba con estudios posprimaria); $42 \%$ informó dedicarse a labores agrícolas (entre las mujeres, $67 \%$ declaró dedicarse a labores del hogar), y $96 \%$ carece de seguridad social. En cuanto a las condiciones de la vivienda, $67 \%$ poseen piso de tierra, $25 \%$ carecen de electricidad, en $85 \%$ de ellas cocinan con leña, en $43 \%$ no se dispone de agua dentro de la vivienda y sólo en $13 \%$ de las viviendas se cuenta con refrigerador.

En 93 de las 99 viviendas se almacenaba el agua para consumo humano (en el resto, se tomaba directamente de la llave). En 24 de éstas se almacenaba en cubetas, 44 en ollas de peltre y 25 en cántaros. El agua estaba tapada en 61 viviendas y en 32 no. Asimismo, en 54 viviendas se refirió hervir el agua antes de consumirla, en 32 la tomaban sin hervir y en 13 no se obtuvo información al respecto.

Sólo 33\% de las muestras de agua obtenidas de las 99 viviendas estudiadas, así como sólo una de las 10 muestras de agua extradomiciliarias, fueron de buena calidad. Ello representa que, de manera global, apenas $31 \%$ de las muestras analizadas fueron de buena calidad bacteriológica. Debe destacarse que en las 36 muestras de agua (de un total de 46 muestras de agua que dieron positivo al grupo de coliformes fecales) a las que se les realizó la prueba confirmatoria de fermentación de lactosa, se obtuvo un crecimiento positivo para Escherichia coli.

Las diferencias observadas en la CBA, según el tipo de recipiente para su almacenamiento en las viviendas, no llegaron a ser estadísticamente significativas (cuadro III). Por su parte, el hecho de que el agua se encontrara o no tapada, así como si era o no hervida para su consumo, sí mostró asociación estadísticamente significativa con la CBA. Se observó una mejor CBA en muestras de agua cuyo recipiente de almacenamiento estaba tapado $(n=61)$ que en aquellas que lo tenían sin tapar $(n=32)$ : los porcentajes con buena CBA fueron 39 y 19\%, respectivamente. Asimismo, en las muestras provenientes de hogares que refirieron hervir el agua para tomar $(n=54)$ se encontró una mayor proporción de muestras de agua de buena calidad bacteriológica (41\%), que en aquéllas muestras procedentes de viviendas cuyos habitantes dijeron no hervirla $(19 \%, n=32$; cuadro III).

Por su parte, las diferencias observadas en la CBA, según indicadores demográficos, no fueron estadísticamente significativas: en las viviendas de localidades urbanas $(n=16)$ hubo una mayor proporción de muestras de buena CBA respecto a las rurales $(n=93)$ : 
44 versus $24 \%$. Situación similar se observó en las viviendas donde el jefe del hogar no hablaba lengua indígena $(n=74)$, respecto a las que sí la hablaba $(n=25)$, con 35 y $24 \%$, respectivamente. Finalmente, en las viviendas donde no hubo niños menores de cinco años $(n=22)$ la CBA fue buena en $45 \%$, en tanto que en aquellas donde sí hubo niños ( $n=77)$ lo fue en $29 \%$ de las muestras.

No se encontró diferencia alguna en la CBA según la ocupación del jefe del hogar y los diversos indicadores de la vivienda analizados. Respecto a la escolaridad del jefe del hogar, si bien se encontró una mejor CBA en hogares cuyo jefe de hogar tenía cuatro o más años de escolaridad $(n=28)$ respecto a los de menor escolaridad ( $n=68), 46$ versus $26 \%$, respectivamente, dicha diferencia no fue significativa en términos estadísticos. Similar situación se observó en cuanto al grado de marginación socioeconómica del municipio (40\% de las 43 muestras de agua provenientes de viviendas de comunidades de alta marginación fueron de buena calidad, versus $24 \%$ de las 66 muestras provenientes de viviendas de localidades de muy alta marginación) (cuadro III).

La diferencia observada en la proporción de muestras de buena CBA, entre los hogares de localidades que se encontraban a menos de una hora de la unidad de salud más cercana $(n=53)$, respecto a las que se ubicaban a una hora o más $(n=46), 40$ versus $24 \%$, no fue estadísticamente significativa (cuadro III).

No se encontró diferencia alguna en la presencia de diarrea en los últimos 15 días, según la CBA hallada en las viviendas (cuadro IV).

De los principales parásitos detectados en los 255 niños en los que se obtuvieron tres muestras de heces,

\section{Cuadro III \\ Calidad bacteriológica del agua, según indicadores analizados. Región Fronteriza de Chiapas, México, 1998}

\begin{tabular}{|c|c|c|}
\hline Indicador & Buena calidad bacteriológica \% & Razón de momios (IC 95\%) \\
\hline \multicolumn{3}{|l|}{ Condiciones de almacenamiento } \\
\hline \multicolumn{3}{|l|}{ Sitio de almacenamiento $\ddagger$} \\
\hline Cubeta $(n=24)$ & 41.7 & $2.14(0.65-7.08)$ \\
\hline Cántaro $(n=25)$ & 36.0 & $1.69(0.51-5.58)$ \\
\hline Olla de peltre $(n=44)^{*}$ & 25.0 & 1.00 \\
\hline \multicolumn{3}{|l|}{ Sitio de almacenamiento con tapa $\mathrm{a}^{\ddagger}$} \\
\hline Si $(n=61)$ & 39.3 & $2.81(1.01-7.84)$ \\
\hline No $(n=32)^{*}$ & 18.8 & 1.00 \\
\hline \multicolumn{3}{|l|}{ ¿Se hierve el agua? } \\
\hline Si $(n=54)$ & 40.7 & $2.98(1.05-8.43)$ \\
\hline No $(n=32)^{*}$ & 18.8 & 1.00 \\
\hline \multicolumn{3}{|l|}{ Indicadores socioeconómicos } \\
\hline \multicolumn{3}{|l|}{ Escolaridad del jefe del hogar } \\
\hline 4 y más años de estudio $(n=28)$ & 46.0 & $2.41(0.87-6.67)$ \\
\hline $0-3$ años de estudio $(n=68)^{*}$ & 26.0 & 1.00 \\
\hline \multicolumn{3}{|c|}{ Grado de marginación socioeconómica del municipio\# } \\
\hline Alta marginación $(n=43)$ & 40.0 & $2.04(0.82-5.10)$ \\
\hline Muy Alta marginación $(n=66)^{*}$ & 24.0 & 1.00 \\
\hline \multicolumn{3}{|l|}{ Indicador de acceso a los servicios de salud } \\
\hline \multicolumn{3}{|c|}{ Distancia de la comunidad a la unidad de salud más cercana } \\
\hline$<$ I hora $(n=53)$ & 40.0 & $2.09(0.80-5.49)$ \\
\hline$\geq$ I hora $(n=46)^{*}$ & 24.0 & 1.00 \\
\hline
\end{tabular}


Entamoeba histolytica, Ascaris lumbricoides, Entamoeba coli y Gardia lamblia, sólo la prevalencia de E. histolytica mostró asociación estadísticamente significativa con la CBA. Asimismo, sin llegar a ser estadísticamente significativa, se encontró una mayor tendencia a estar parasitados en los menores cuyas viviendas el agua fue de mala calidad que en aquellos menores en cuya vivienda el agua fue de buena calidad (cuadro V).

\section{Discusión}

Los resultados obtenidos sobre la CBA para consumo humano revelan niveles de contaminación que la hacen no apta para su consumo en la mayoría de las comunidades estudiadas, hallazgo consistente con lo notificado en otros estudios efectuados en el ámbito nacional. ${ }^{3,4}$ En dos de cada tres viviendas de la región estudiada y en prácticamente la totalidad de las fuentes de abastecimiento de aquellas localidades que carecen de sistemas formales de abastecimiento de agua para consumo humano, ésta se encuentra contaminada por bacterias del grupo coliformes, lo que la hace potencialmente peligrosa para la salud humana, ${ }^{17}$ sobre todo si se toma en cuenta que la totalidad de las muestras de agua a las que se les practicaron pruebas confirmatorias ( $n=36$ de 46 que fueron positivas al grupo de coliformes fecales) dieron positivo a Escherichia coli, bacteria considerada como un indicador más preciso de contaminación en aguas de zonas rurales y tropicales. ${ }^{19,20}$

En este sentido, debe señalarse que los resultados obtenidos de la magnitud de muestras de agua con

\section{Cuadro IV \\ Diarrea percibida en los I5 días previos A LA ENCUESTA, SEGÚN CALIDAD BACTERIOLÓGICA DEL AGUA DE LAS VIVIENDAS ANALIZADAS. Región Fronteriza de Chiapas, México, MARZO A SEPTIEMBRE DE 1998}

Edad de los niños (en años)

\begin{tabular}{lcc}
\hline-4 & $22.2(n=27)$ & $19.2(n=73)$ \\
\hline $5-\mid 4$ & $7.8(n=77)$ & $8.3(n=145)$ \\
\hline Global & $I I .5(n=104)$ & $I I .9(n=218)$
\end{tabular}

* Diarrea informada como morbilidad percibida en los últimos 15 días por las madres de los niños y niñas de I a I4 años de edad. Incluye las siguientes menciones dentro de la encuesta:" diarrea","chorrillo","hacer del baño con moco y sangre","disentería","salmonelosis","obrar mucho", "hacer mucho del baño","tifoidea"

\section{Cuadro V \\ ENTERoparasitosis EN MENORES de I A I 4 AÑos de EDAD, SEGÚN CALIDAD BACTERIOLÓGICA DEL AGUA. Región Fronteriza de Chiapas, México, 1998.}

Calidad bacteriológica del agua en la vivienda
$\begin{array}{ccc}\text { Buena } & \text { Mazón de momios } \\ \text { (IC 95\%) }\end{array}$

Entamoeba histolytica

\begin{tabular}{llll} 
I-4 años & $38.1 \%(n=2 I)$ & $45.3 \%(n=64)$ & I.35 $(0.49-3.69)$ \\
\hline $5-14$ años & $44.6 \%(n=56)$ & $63.2 \%(n=114)$ & $2.13(I . I I-4.07)$ \\
\hline Global & $42.9 \%(n=77)$ & $56.7 \%(I 78)$ & I.75 (I.02-3.00)
\end{tabular}

\begin{tabular}{llll}
$\begin{array}{l}\text { Giardia lamblia } \\
\text { I-4 años }\end{array}$ & $38.1 \%(n=2 I)$ & $21.9 \%(n=64)$ & $0.46(0.16-1.32)$ \\
\hline 5-I4 años & $25.0 \%(n=56)$ & $20.2 \%(n=114)$ & $0.76(0.36-1.62)$ \\
\hline Global & $28.6 \%(n=77)$ & $21.0 \%(I 78)$ & $0.72(0.40-1.30)$
\end{tabular}

Entamoeba coli

\begin{tabular}{lllr}
$I-4$ años & $\mid 4.3 \%(n=2 I)$ & $26.6 \%(n=64)$ & $2.17(0.57-8.3 I)$ \\
\hline $5-14$ años & $4 I .1 \%(n=56)$ & $36.0 \%(n=114)$ & $0.8 I(0.42-1.55)$ \\
\hline Global & $33.8 \%(n=77)$ & $32.6 \%(I 78)$ & $0.95(0.54-1.67)$
\end{tabular}

Ascaris lumbricoides

\begin{tabular}{llll}
$I-4$ años & $9.5 \%(n=2 I)$ & $21.9 \%(n=64)$ & $2.66(0.55-12.83)$ \\
\hline $5-14$ años & $7.1 \%(n=56)$ & $12.3 \%(n=114)$ & $I .82(0.57-5.8 I)$ \\
\hline Global & $7.8 \%(n=77)$ & $15.7 \%(I 78)$ & $2.21(0.88-5.58)$
\end{tabular}

Con algún parásito

\begin{tabular}{llll} 
I-4 años & $57.1 \%(n=2 I)$ & $68.8 \%(n=64)$ & $1.65(0.60-4.55)$ \\
\hline $5-14$ años & $64.3 \%(n=56)$ & $72.8 \%(n=114)$ & $1.49(0.75-2.95)$ \\
\hline Global & $62.3 \%(n=77)$ & $71.3 \%(I 78)$ & $I .50(0.86-2.64)$
\end{tabular}

mala calidad pueden considerarse como la cifra basal de la dimensión del problema, debido básicamente a los siguientes tres motivos: a) si bien el método utilizado para la determinación de CBA posee mayor precisión respecto de otros métodos (por ejemplo, el de tubos múltiples) su capacidad es limitada para estudiar aguas con elevada turbidez (sólidos) o aguas que contengan bacterias no coliformes. ${ }^{17,21}$ En este estudio algunas muestras obtenidas presentaban alta turbidez; b) en las comunidades de mayor marginación se tuvieron dificultades logísticas para el traslado de muestras al laboratorio que implicaron, en algunas ocasiones, retrasos hasta de 24 horas para su procesamiento, y c) en este estudio no se llevaron a cabo análisis de otro tipo de contaminantes como aquéllos de origen químico.

En 28 de las 32 comunidades estudiadas el agua no recibe tratamiento alguno y en cuatro el tanque de agua desde donde se distribuye el líquido a la comu- 
nidad, según información de los habitantes, aparentemente recibe tratamiento con cloro. En este estudio, de las 21 muestras de agua analizadas de estas cuatro comunidades, a pesar de no haber utilizado agente desclorante alguno en su conservación y transporte, 16 mostraron contaminación.

Por otra parte, destacan los resultados obtenidos en relación con la CBA según las condiciones de almacenamiento del líquido: tal como se esperaba, se encontró mejor CBA en hogares que la almacenaban en un recipiente tapado y que la hervían, que en aquéllos que no lo hacían. Asimismo, los resultados sugieren que la calidad del agua es menor en las comunidades rurales que en las urbanas, en las de muy alta marginación que en las de alta marginación socioeconómica, en viviendas cuyo jefe de hogar tiene bajo nivel de escolaridad y en grupos indígenas.

Se debe resaltar también que en dos de cada tres casas en donde hay niños menores de cinco años el agua para consumo es de mala calidad, lo cual por su importancia se debe considerar debido a que es uno de los grupos poblacionales más vulnerables a padecimientos gastrointestinales. Asimismo, ninguno de los indicadores de la vivienda analizados, especialmente el tipo de piso (con o sin recubrimiento) mostró asociación con la CBA. Prácticamente, en la totalidad de las viviendas estudiadas que tenían la mayor parte del piso con recubrimiento, el cuarto destinado a la cocina no lo tenía y, en consecuencia, las posibilidades de contaminación del agua fueron semejantes a las viviendas con piso sin recubrimiento.

Con relación a la CBA y al acceso a los servicios de salud (medido en este estudio por la distancia de las comunidades a la unidad de salud más cercana $)^{15}$ se encontró, aunque las diferencias observadas no fueron estadísticamente significativas, que los resultados sugieren que existe una CBA inferior en las viviendas de comunidades que están a una hora o más de distancia a la unidad de salud más cercana que en las que están a menos de una hora. La importancia de este indicador radica en que se pudiera constituir en un parámetro del alcance y efectividad de los programas de saneamiento básico por parte de los servicios de salud, ya que una de las principales actividades de los servicios de salud en el ámbito comunitario es promover que se hierva el agua para consumo humano.

Respecto a la ausencia de relación entre la CBA y presencia de diarreas en los últimos 15 días previos al estudio, se tienen dos posibles situaciones que pudieran contribuir a explicar dicha situación: que las condiciones de higiene son relativamente similares en la gran mayoría de las viviendas estudiadas o que las madres de los menores estudiados de hogares en con- diciones de mayor pobreza y con menores niveles educativos perciban con menor frecuencia este tipo de padecimientos entre sus hijos.

Finalmente, en lo que toca a la relación entre la CBA y enteroparasitosis el que la presencia de Entamoeba histolytica sí mostrara asociación con la CBA en el grupo de niños de 5 a 14 años de edad es de suma importancia, debido a que E. histolytica es, de todas las especies de amibas, la de mayor importancia clínica ya que es un parásito patógeno. ${ }^{28}$ Asimismo, si bien las diferencias observadas en la proporción de parasitados (en forma global y por Ascaris lumbricoides) entre los niños procedentes de viviendas con y sin agua contaminada, no fueron estadísticamente significativas, sí se observó una tendencia de una mayor parasitosis en los hogares con mala CBA.

En este sentido, debe señalarse que un mayor número de muestras de agua analizadas hubiera incrementado notablemente la capacidad de análisis de todas las variables estudiadas en relación a la CBA. Sin embargo, las dificultades de acceso a la zona estudiada (geográficas, climáticas y las inherentes al conflicto armado iniciado en 1994), así como limitaciones presupuestales, hicieron inviable la posibilidad de analizar un mayor número de muestras de agua para consumo humano.

A pesar de ello, los hallazgos obtenidos revelan la necesidad de desarrollar estudios que evalúen y resuelvan la problemática que representa la deficiente CBA para consumo humano en zonas de alta marginación socioeconómica. Chiapas es de los estados mexicanos con mayor incidencia en varias enfermedades asociadas directa o indirectamente al consumo del agua. ${ }^{10}$ La falta de atención de los factores condicionantes de dicha situación, entre los que destacan los relativos al mejoramiento de las condiciones higiénico-sanitarias, incluidos los de la calidad del agua, propiciará que Chiapas continúe siendo, como hasta ahora, uno de los estados que aporte el mayor número de enfermedades gastrointestinales en el país, con sus respectivas implicaciones en términos de retraso en el crecimiento y malnutrición de menores, mortalidad y costos de atención, tanto para los servicios de salud como para la población.

En conclusión, los resultados obtenidos revelan la necesidad de desarrollar medidas que mejoren el abastecimiento y la CBA para consumo humano en el área estudiada y, presumiblemente, en otras áreas con condiciones similares. Estas medidas se deberán dirigir tanto a las fuentes de obtención de agua como a las condiciones en que ocurre su almacenamiento. ${ }^{29} \mathrm{En}$ el primer caso, en las comunidades que carecen de sistemas de distribución de agua, se podrían desarrollar 
sistemas relativamente sencillos mediante mangueras que fueran de las fuentes de abastecimiento de agua a tanques comunitarios y, desde ahí, y también mediante mangueras, a las viviendas. En dichos tanques se podrían instalar sistemas de purificación de agua, bien sea con métodos de cloración o con el uso de plata coloidal o similares. En el caso de las condiciones de almacenamiento del agua podría ser útil fomentar en la población el uso de contenedores de boca estrecha, cerrados con tapa y especialmente diseñados para evitar la contaminación del agua antes de su consumo. ${ }^{29}$

También resulta evidente la necesidad de desarrollar una campaña de educación para la salud dirigida a población general. Esta campaña tendría que perseguir al menos los siguientes objetivos: a) sensibilizar a la población sobre las ventajas de consumir agua de buena calidad y los peligros del consumo de agua de mala calidad; $b$ ) incrementar el uso de agua hervida o de sustancias bactericidas (plata coloidal, nitrato de plata, cloración, etc.); c) mejorar el manejo adecuado del agua como, por ejemplo, el uso de recipientes adecuados para su almacenamiento, el lavado de manos después de ir al baño y antes de la preparación de alimentos, y d) incrementar el cuidado de las fuentes de abastecimiento de agua potable por parte de las comunidades.

\section{Agradecimientos}

Los autores agradecemos al Centro de Investigaciones en Paludismo, de Tapachula, Chiapas, por las facilidades otorgadas para el procesamiento de muestras. También agradecemos la participación de María Luisa Estudillo, Alejandro Flores, Zulma Barrios, Trinidad Pérez Aguilar, Roberto Solís, de El Colegio de la Frontera Sur, así como a David Prat (de la Universidad Autónoma de Barcelona) por su invaluable participación en el trabajo de campo y análisis de datos. A las Q.F.B. Olga Ruth Gálvez y Margarita Pérez, así como a Martín Moreno, por su participación en el procesamiento de muestras y a la doctora María del Mar García Gil por sus valiosos comentarios en la preparación del manuscrito.

\section{Referencias}

I. Gutiérrez-Avila H, Becerra W, Brust C. Calidad de agua potable e incidencia de gastroenteritis en dos ciudades del estado de Sonora. Salud Publica Mex 1989;31:299-304.

2. Organización Panamericana de la Salud, Organización Mundial de la Salud. Agua, nuestro planeta y nuestra salud. Informe de la Comisión de
Salud y Medio Ambiente de la Organización Mundial de la Salud.Washington, D.C.: OPS, OMS, 1993.

3. Luna-Núñez H. El agua en México: una visión general. En:Arias-Chávez J, Luna-Núñez H,Acosta GA, Escolero FO, Huízar AR, Ezcurra E et al, ed. El agua: recurso vital. Huajuapan de León (Oaxaca), México: Universidad Tecnológica de la Mixteca, 1993:I I-19.

4.Arias-Chávez J. El agua en el mundo. En:Arias-Chávez J, Luna-Núñez $\mathrm{H}$, Acosta GA, Escolero FO, Huízar AR, Ezcurra E et al. El agua: recurso vital. Huajuapan de León (Oaxaca), México: Universidad Tecnológica de la Mixteca, 1993:5-10.

5.Angeles-Chimal J, Sánchez-Salinas E, Ortiz-Hernández M, Olvera-Velona A. Calidad microbiológica del agua de la "Presa Lorenzo Vázquez", municipio de Tlaquiltenango, Morelos. Resultados preliminares. Rev Int Contam Ambient 1994;suppl 2: 25.

6. Isaac-Márquez AP, Lezama-Dávila CM, Ku-Pech PP, Tamay-Segovia P. Calidad sanitaria de los suministros de agua para consumo humano en Campeche. Salud Publica Mex 1994;36: 355-36I.

7. Cheesbroug M. Medical laboratory manual for tropical countries. Volume II: Microbiology. Cambridge (MA): Tropical Health Tecnology, 1995: 206-224.

8. Instituto Nacional de Estadística, Geografía e Informática. XI Censo General de Población y Vivienda 1990. México, D.F: INEGI, 1990.

9.Yáñez VL. Epidemiología. Sistema Nacional de Vigilancia Epidemiológica. Secretaría de Salud, Sistema Unico de Información. Boletín de Epidemiología 1997;14(39): I-3.

10. Secretaría de Salud. Morbilidad 1998. México, D.F.: SSA, 1998.

II. Secretaría de Salud. Dirección General de Epidemiología. Información epidemiológica de morbilidad 1998. México, D.F.: SSA, 1998.

12. Secretaría de Salud, Dirección General de Estadística e Informática. Principales resultados de la estadística sobre mortalidad en México, 1997. Salud Publica Mex 1998;40:517-523.

13. Instituto Nacional de Estadística, Geografía e Informática. Chiapas. Conteo de población y vivienda 1995. Resultados definitivos. Tabulados básicos. México, D.F.: INEGI, 1996.

14. Consejo Nacional de Población. Indicadores socioeconómicos e índice de marginación municipal, México, 1990. México, D.F.: Conapo, 1993. 15.TheWorld Bank.World development report 1997. The state in a changing world. Washington, D.C.: Oxford University Press, 1997

16. Secretaría de Salud. Norma Oficial Mexicana para la Salud Ambiental, Agua para Uso y Consumo Humano. Límites permisibles de calidad y tratamiento a que debe someterse el agua para su potabilización. NOM |27-SSA I-1994. México, D.F: Diario Oficial de la Federación. 18 de enero de $1996: 4 \mid-45$.

17. American Public Health Association, American Water Works Association, Water Environment Federation. Métodos normalizados para el análisis de aguas potables y residuales. Madrid: Díaz de Santos, 1992.

18. Parrilla MC, Saldate EO, Nicoli LM. Manuales de técnicas y procesamiento de laboratorio para el análisis microbiológico de agua potable. Serie de manuales técnicos. México, D.F.: Secretaría de Salud, 1989:8-20.20. 19. World Health Organization. Guidelines for drinking-water quality. 2a. edición. Health criteria and other supporting information. Ginebra:WHO, 1996;Vol.:940-949.

20.World Health Organization. Guidelines for drinking-water quality. Health criteria and other supporting information. Ginebra:WHO, 1998;Addendum to vol. 2:28I-283.

21. Sandoval A, Carlos G. Adiestramiento para la prevención y control de las enfermedades gastrointestinales en el sector en el agua. Determinación de coliformes fecales. 2a. edición. México, D.F.: Secretaría de Agricultura y Recursos Hidráulicos, Comisión Nacional del Agua, Instituto Mexicano de Tecnología del Agua, 1992;Manual Núm. 6.

22. Organización Panamericana de la Salud. Guías para la calidad de agua potable. Aspectos microbiológicos. Washington, DC.: Organización Mundial de la Salud, 1985; I:19-41.24. 
23. Cruz-López A, Cortés-Riveroll R, Valerdi-Minor G, González E. Uso masivo de la coproparasitoscopía con FAF. Salud Publica Mex 1989;31: 536-540.

24. Navarrete-Espinosa J, Navarrete-Cadena E, Escobedo J, Escandón-Romero C. Validación de la prueba de coproparasitoscopía de Faust con preservador a base de fenol, alcohol y formol (PAF). Rev Med Inst Mex Seguro Soc 1993;31:151-155.

25. Giono-Cerezo S, Escobar-Guitérrez A, Valdespino JL, ed. Diagnóstico de laboratorio de infecciones gastrointestinales. México, D.F.: Secretaría de Salud, Instituto Nacional de Diagnóstico y Referencia Epidemiológicos, 1994:4I I-432.
26. Linch MJ, Stanley SR, Mellor LD, Spare PD, Inwood M. Métodos de laboratorio. México, D.F.: Interamericana, 1988.

27. Carrol FE, Farr RP, Clifton JR. Parasitología clínica. México, D.F.: Salvat Mexicana, 1974.

28. Martínez-Palomo A. Entamoeba histolytica. En: Giono-Cerezo S, Escobar-Guitérrez A, Valdespino JL, ed. Diagnóstico de laboratorio de infecciones gastrointestinales. México, D.F.: Secretaría de Salud, Instituto Nacional de Diagnóstico y Referencia Epidemiológicos, 1994:45I-463. 29. World Health Organization. The world health report 1996. Fighting disease fostering development. Ginebra:WHO, 1996. 